\title{
A longitudinal study of risk factors for the occurrence, duration and severity of menstrual cramps in a cohort of college women
}

\author{
Siobán D. Harlow Assistant Professor, Meekyong Park Research Assistant \\ Department of Epidemiology, School of Public Health, University of Michigan, Ann Arbor, USA
}

Objective To describe how menstrual cramps vary from cycle to cycle within a woman over time. To examine the influence of weight and lifestyle factors on occurrence, duration, and severity of menstrual pain.

Design A one-year prospective menstrual diary study.

Participants One hundred and sixty-five women aged 17 to 19 years entering a local university in 1985 .

Main outcome measures The occurrence, length, and maximum severity of pain during a menstrual period.

Results Menstrual pain occurred during $71.6 \%$ of observed menstrual bleeds, most commonly beginning the first day of menses. The median duration was two days. Sixty percent of women reported at least one episode of severe pain, while $13 \%$ reported severe pain more than half the time. Earlier age at menarche and long menstrual periods increased the occurrence, duration and severity of pain. In smokers, cramps tended to last longer. Being overweight was an important risk factor for menstrual cramps and doubled the odds of having a long pain episode. Frequent alcohol consumption decreased the probability of having menstrual cramps, but in women who had pain it increased duration and severity. Physical activity was not associated with any pain parameter.

Conclusions Women who have pain lasting three days are an important target group for prophylactic therapy. The occurrence and severity of menstrual cramps is influenced by potentially modifiable characteristics including weight, smoking, and alcohol consumption. Doctors may wish to counsel women presenting with dysmenorrhoea about the importance of healthy lifestyles and about the inefficacy of alcohol consumption as a treatment for dysmenorrhoea.

\section{INTRODUCTION}

Dysmenorrhoea is a common gynaecological complaint. In cross-sectional surveys, $30 \%$ to $60 \%$ of women of reproductive age report experiencing pain during menstruation with the proportion of women who report severe pain ranging from $7 \%$ to $15 \%^{1-13}$. Young adult women aged 17 to 24 years report a somewhat higher prevalence with estimates ranging from $67 \%$ to $72 \% \%^{1,4,9-12}$. Discrepancies between studies of prevalence are largely attributable to differences in the exact age of study populations and to variable definitions of dysmenorrhoea (e.g. any versus moderate pain, or ever versus usual experience). Age at menarche $e^{1,4,5,8}$, parity ${ }^{1,5,8}$, menstrual characteristics $^{1,5,14}$ and smoking ${ }^{3,6,7,13,14}$ have also been associated with the presence and severity of menstrual cramps.

Correspondence: Dr S. D. Harlow, Department of Epidemiology, 109 Observatory Street, Ann Arbor, Michigan 48109, USA.
To date, no study has described how the occurrence and severity of menstrual pain changes from cycle to cycle within a woman, and only one longitudinal study has prospectively examined change in the prevalence and severity of dysmenorrhoea within women over time ${ }^{8}$. Using data from menstrual diaries kept by a cohort of college women for one year, the present study describes how the experience of menstrual pain varies within women during the study period. We also prospectively examine how menstrual cycle characteristics, weight, and lifestyle factors influence the occurrence, duration, and severity of menstrual cramps and of menstrual disability.

\section{METHODS}

In 1985 women aged 17 to 19 years entering a local state university enrolled in a one-year menstrual diary study designed to evaluate the association between weight, physical activity and stress and menstrual cycle characteristics. Details of the study 
methods have been presented elsewhere ${ }^{15,16}$. The study was approved by Institutional Review Boards at Johns Hopkins School of Hygiene and Public Health and at the local university from which participants were recruited. Briefly, 766/908 women (84\%) entering their freshmen year completed a screening questionnaire after giving informed consent to determine eligibility for the diary study. Women who were pregnant, were using birth control pills or other hormonal medications, had primary amenorrhoea or unknown menarche status were not eligible for the study. To increase homogeneity of the sample, two women who were married and had children were also excluded. No women reported using an intrauterine contraceptive device. Seventy-six percent of the 203 ineligible women were not eligible because they were taking oral contraceptives.

Of the 563 eligible women, 179 volunteered to participate within the first month of starting college and were enrolled in the diary study after again giving informed consent. The willingness of eligible women to participate was not related to menstrual characteristics or severity of menstrual cramps as reported on the screening questionnaire. No difference between participants and nonparticipants was observed in their mean age of menarche $(12.7$ versus 12.8 years; $P=0.31$ ), mean reported average cycle length $(28.6$ versus 29.0 days; $P=0.57)$, mean reported average bleed duration ( 4.9 versus 5.0 days; $P=0.46)$, history of having missed a cycle $(40.8 \%$ versus $40 \cdot 1 \% ; P=0.88)$, or the percentage reporting that their cycle length varied $(56.4 \%$ versus $50.8 \%$; $P=0.22$ ). Usual severity of menstrual cramps also did not vary between participants and nonparticipants. Among participants $28.7 \%$ reported usually having no pain, $29.8 \%$ reported mild pain, $27.5 \%$ moderate pain and $14.0 \%$ severe pain, compared with reports of $33.9 \%, 27.6 \%, 20.3 \%$ and $18.2 \%$ in nonparticipants, respectively $(P=0 \cdot 15)$.

Eight women had started taking birth control pills at the time of enrolment, five never returned a monthly record, and one woman never reported a menstrual bleed, leaving 165 women eligible for this analysis. A woman's record was censored when she dropped out of the study, when she became pregnant and continued the pregnancy, when she started using birth control pills or other hormonal medication, or at the end of the study year. Although the effect of oral contraceptives on menstrual pain is of interest, there are insufficient observations of women on the pill to address this question. Seventy-four women (45\%) were censored prior to the end of the study year, half because they withdrew from the study and half because they started using hormonal contraception. One woman was censored because of pregnancy. All data until the time of censoring are used in this analysis. Duration of participation was not associated with length or mean severity of a pain event, but uncensored women had more opportunity to contribute an episode with a maximum pain level of five. The distribution of risk factors was similar between censored and uncensored women.

At the time of enrolment, participants completed a questionnaire which obtained information on menstrual history and baseline weight, level of physical activity, perceived stress, dieting behaviour, alcohol consumption and smoking status. Throughout the course of the study, women maintained a daily record of their menstrual bleeding and experience of menstrual cramps or backache. Severity of menstrual pain was indicated by a score of 1 to 5 , where 1 represented minimal pain and 5 represented unbearable pain. After each bleeding episode women noted whether they had taken pills for pain, and if so what type, and whether they had missed school, work, or other activity. Self-administered questionnaires were completed monthly to obtain follow up information on risk factors, contraceptive use and pregnancy.

\section{Menstrual data}

Definitions recommended by the World Health Organisation were used to summarise the bleeding data $^{17}$. Menstrual cycle length was calculated by counting the number of days from the first day of one bleeding episode up to and including the day before the next bleeding episode. Length of a bleeding episode was calculated by counting the number of days from the start of a bleeding episode up to and including the day before the start of a bleeding-free interval. A bleeding-free interval was defined as consisting of no bleeding for at least two days. A bleeding episode could not consist of a single day of spotting (bleeding for which no protection was needed or bleeding that would fill less than one tampon or napkin). When a woman failed to return a monthly diary, all menstrual and pain variables were coded as missing. In this analysis, bleed length was categorised as one to seven days and more than seven days, menstrual history variables included age at menarche and history of having at least one menstrual cycle longer than six weeks.

\section{Menstrual pain data}

Examination of pain patterns showed that more than one discrete pain episode could be associated with the same bleeding episode. Therefore a pain event was defined as a group of linked pain episodes associated with the same bleeding episode in which the 
pain-free interval between pain episodes was not more than four days. Pain episodes could begin before, during or after a bleeding episode or in the middle of a menstrual cycle unassociated with menstruation. After examining distributions of the timing of onset of pain events in relation to bleeding episodes, five days was the outside limit observed for a pain episode to start before and overlap the menstrual period. Thus pain episodes occurring within five days of or during a bleeding episode were considered to be bleed-associated. This analysis was limited to pain events associated with menstrual bleeding. For each pain event the following parameters were calculated: length, number of pain episodes, maximum level of pain reported, mean level of pain reported, the sum of the pain level for each pain day in an event, pain pattern (constant, increasing, decreasing and other) and the timing of onset (before, during, after the bleed). The length of a pain event was calculated by counting the number of days from the first day of pain in the first episode up to and including the last day of pain in the last episode. Measures of menstrual disability included whether a woman reported taking a pill for pain, and whether she had missed any activity or stayed in bed.

\section{Covariates}

Benn's index ${ }^{18,19}$ was used as an index of weight corrected for height, with the appropriate power, based on self-reported weight and measured height, calculated to be $2 \cdot 6$. Smoking behaviour was defined by current smoking status (yes/no). Frequency of alcohol consumption was categorised as infrequent (one drink or less per week) or frequent (two or more drinks per week). Perceived stress was measured using the four-item Perceived Stress Scale ${ }^{20}$. An additional measure of life stress was whether or not the student was living away from home. Although major life events were examined, neither loss events nor gain events were associated with any pain or disability parameter. Similarly, level of physical activity was not associated with pain or disability. Therefore neither variable is considered further here (data not shown).

\section{Analysis}

In order to describe the occurrence and severity of menstrual pain and associated disability, frequency distributions of pain parameters were calculated in two ways: 1 . by giving equal weight to each observed pain event disregarding how many events were contributed by each woman (by-pain-event analysis) and 2 . by giving equal weight to each woman (by-woman analysis). For example, in the by-pain-event analysis the mean length of all observed pain events or the proportion of all events in which pain medication was used is presented. In the by-woman analysis the mean of each woman's mean pain length or the proportion of women who ever reported using pain medication is presented. In order to understand how length and severity of pain varied from one menstrual episode to the next within an individual, the probability of transition from one pain level to another in two consecutive menstrual periods ${ }^{16}$ was estimated.

Logistic regression with robust variance estimation $^{21}$ (which accounts for the lack of independence between repeated observations in the same individual) was used to model the probability of having or not having pain. A factor analysis identified three common factors, duration, severity and disability, from the observed pain variables. A second set of logistic regressions was used to model the probability of having long duration (pain for more than two days) or moderate/severe pain (a maximum pain level of 3 or more), or missing an activity because pain had occurred. Logistic regression analyses were also used to model risk factors for medication use because of its clinical interest. Additional analyses examined three aspects of pain pattern: 1. decreasing versus other patterns, 2. multiple episodes in one pain event, and 3. the probability of pain onset prior to the onset of bleeding. Menstrual characteristics, examined as potential risk factors, included length of the preceding cycle and length of the concurrent bleeding episode.

The covariate value assigned to a given pain event was the average value of that variable during the first 14 days of the preceding menstrual cycle. Since covariate information was obtained during the previous menstrual cycle, only those bleeding episodes for which the preceding menstrual cycle was observed are included. Very short cycles are unlikely to actually be menstrual cycles and very long cycles represent a distinctly different ovarian process. Therefore, based upon our previous analysis of the distribution of menstrual cycle lengths in this dataset ${ }^{16}$, we excluded cycles shorter than 17 days $(n=17)$ or longer than 43 days $(n=60)$ were excluded. This paper thus analyses acute effects and addresses the question of how differences in the level of a risk factor at the start of a menstrual cycle effect the pain experience at the end of that cycle.

\section{RESULTS}

Age of menarche in the 165 eligible women ranged from 10 to 16 , with a median age of 13 years. At enrolment, $43 \%$ reported a history of having had long 
Table 1. Distribution of duration and severity of menstrual cramps (by-pain-event and by-woman) for 165 women aged 17-19 years old. Values are shown as $n$, mean (range), and 5 th, 50 th and 95 th centiles.

\begin{tabular}{|c|c|c|c|c|c|c|c|c|c|c|c|c|}
\hline & \multicolumn{6}{|c|}{ By-pain-event } & \multicolumn{6}{|c|}{ By-woman } \\
\hline & $n$ & Mean & (Range) & 5 th & 50th & 95th & $n$ & Mean & (Range) & 5 th & 50 th & 95th \\
\hline \multicolumn{13}{|l|}{ All bleeds } \\
\hline Pain length & 1393 & 1.7 & $(0-11)$ & 0 & 1 & 5 & 165 & $1 \cdot 8^{*}$ & $(0-7)$ & 0 & 1.5 & 4.5 \\
\hline Mean pain level & 1381 & $1 \cdot 7$ & $(0-5)$ & 0 & 2 & 4 & 165 & $1 \cdot 7 * *$ & $(0-4)$ & 0 & 2 & 3 \\
\hline Maximun pain level & 1381 & $2 \cdot 1$ & $(0-5)$ & 0 & 2 & 5 & 165 & $3 \cdot 5 \dagger$ & $(0-5)$ & 0 & 4 & 5 \\
\hline \multicolumn{13}{|l|}{ Bleeds with pain only } \\
\hline Pain length & 997 & $2 \cdot 4$ & $(1-11)$ & 1 & 2 & 6 & 154 & $2 \cdot 3$ & $(1-7)$ & 1 & 2 & 5 \\
\hline Mean pain level & 985 & $2 \cdot 4$ & $(1-5)$ & 1 & $2 \cdot 3$ & 4 & 154 & $2 \cdot 3$ & $(1-4)$ & 1 & $2 \cdot 5$ & 4 \\
\hline Maximun pain level & 985 & $2 \cdot 9$ & $(1-5)$ & 1 & 3 & 5 & 154 & $3 \cdot 8$ & $(1-5)$ & 1 & 4 & 5 \\
\hline
\end{tabular}

*Mean of each woman's mean length. **Mean of each woman's mean level. †Mean of each woman's maximum level.

cycles. Height ranged from $22.8 \mathrm{~cm}$ to $27.9 \mathrm{~cm}$ (median $25.3 \mathrm{~cm}$ ). Weight at baseline ranged from $38.2 \mathrm{~kg}$ to $95.5 \mathrm{~kg}$ (median $125 \mathrm{~kg}$ ). Weight was relatively stable throughout the observation period, with the median monthly change in weight being $0 \mathrm{~kg}$. In contrast to weight there was variation in perceived stress during the school year. The median monthly perceived stress score was 5 (maximum score $=12$ points). Only $20 \%$ of the women reported smoking at baseline and $19 \%$ reported drinking more than once per week. One hundred women lived away from home during at least one semester.

Participants reported a median of nine bleeding episodes (range 1-15 episodes) for a total of 1396 bleeding episodes. Median bleed duration was five days (range 1-19 days). Analyses which examined change in pain characteristics from bleeding episode to bleeding episode or which include information about risk factors required observation of at least two bleeds, and 145 women reported at least one bleed following a menstrual cycle of 17 to 43 days.

Women reported a median of five discrete pain events (range 0-20 events) with pain reported during $1000(71.6 \%)$ of the 1396 observed bleeds. A pain event consisted of more than one discrete pain episode during 73 events, with a maximum of three episodes occurring during a given event. During three menstrual periods two distinct pain events were observed. Cramps most commonly began on the first day of menses $(71 \cdot 1 \%$ of pain events) and began before bleeding started in only $109(10.9 \%)$ instances. The most commonly reported pain patterns were constant severity ( $45.6 \%$ of pain events) and decreasing severity $(31 \cdot 1 \%$ of pain events). Eleven women never reported experiencing menstrual cramps.

Table 1 presents descriptive statistics for the duration and severity of pain episodes giving equal weight to each observation (by-pain-event distribution) and giving equal weight to each woman (by-woman distribution). Although pain events lasted up to 11 days, pain lasted five days or less in $95 \%$ of bleeding episodes with the median duration of dysmenorrhoea being two days, excluding bleeds without pain. Using the maximum pain score to define severity, pain was defined as mild in $37 \%$ (score $=1$ or 2 ), moderate in $30 \%($ score $=3)$, and severe in $33 \%($ score $=4$ or 5$)$ of reported pain events. Sixty percent of women reported at least one episode of severe pain, while $13 \%$ reported having severe pain more than half the time. In the by-pain-event distribution the median value for maximum pain was three, excluding bleeds without pain. In the by-woman distribution the median value for maximum pain level reported was four, which was consistent with the finding that most women in this study experienced at least one episode of severe pain.

Table 2 presents the frequency of indicators of menstrual disability by-event and by-woman. Missing an activity, though experienced occasionally by many women, was an infrequent occurrence. Forty-two percent of the participants reported missing either work, school, or another activity because of menstruation at some point during the study; however, an activity was missed during only $9.8 \%$ of bleeding episodes. Similarly, $37 \%$ of the women indicated that they had remained in bed during at least one bleeding episode, but bedrest only occurred during $10 \%$ of observed menstrual periods. Limitation of activity, when it occurred, generally lasted one day or less. Taking medication for pain was more common as $84 \%$ of women indicated that they had taken a pill for pain, with pain medication being used during $55 \%$ of observed menstrual periods. Acetaminophen, aspirin, and ibuprofen were the most frequently used medications, with each used in about a third of the medicated pain episodes.

Severity and duration of pain tended to vary con- 
Table 2. Frequency of reporting of missed activities and of taking a pain medication (by-pain-event and by-woman) for 165 women aged 17 to 19 years old. Values are shown as $n(\%)$.

\begin{tabular}{|c|c|c|}
\hline & By-pain-event & By-woman (ever reported) \\
\hline \multicolumn{3}{|l|}{ Missed any activity } \\
\hline No & $1208(90 \cdot 2)$ & $95(57 \cdot 9)$ \\
\hline Yes & $131(9 \cdot 8)$ & $69(42 \cdot 1)$ \\
\hline \multicolumn{3}{|l|}{ Missed school } \\
\hline No & $1277(96 \cdot 0)$ & $123(75 \cdot 0)$ \\
\hline Yes & $53(4 \cdot 0)$ & $41(25 \cdot 0)$ \\
\hline \multicolumn{3}{|l|}{ Missed work } \\
\hline No & $1301(97 \cdot 6)$ & $140(85.9)$ \\
\hline Yes & $32(2 \cdot 4)$ & $23(14 \cdot 1)$ \\
\hline \multicolumn{3}{|l|}{ Missed other } \\
\hline No & $1250(93.9)$ & $119(73 \cdot 0)$ \\
\hline Yes & $81(6 \cdot 1)$ & $44(27 \cdot 0)$ \\
\hline \multicolumn{3}{|l|}{ Stayed in bed } \\
\hline No & $1195(89 \cdot 7)$ & $103(62 \cdot 8)$ \\
\hline Yes & $137(10 \cdot 3)$ & $61(37 \cdot 2)$ \\
\hline \multicolumn{3}{|l|}{ Took a pill for pain } \\
\hline No & $599(44 \cdot 7)$ & $27(16 \cdot 4)$ \\
\hline Yes & $740(55 \cdot 3)$ & $138(83 \cdot 6)$ \\
\hline \multicolumn{3}{|l|}{ Medication } \\
\hline Acetominophen & $212(15 \cdot 8)$ & $75(54 \cdot 7)$ \\
\hline Aspirin & $257(19 \cdot 2)$ & $32(26 \cdot 2)$ \\
\hline Ibuprofen & $242(18 \cdot 1)$ & $62(45 \cdot 3)$ \\
\hline
\end{tabular}

siderably from menstrual period to menstrual period. Tables 3 and 4 present data on the probability of having a specified duration or severity during the current bleeding episode according to the level of pain in the previous bleeding episode. If a woman had no pain during her previous bleed, $45 \%$ of the time she would have no pain during her current menstrual period. If such a woman did experience pain, it was most likely to last only one to two days, but could be of any severity. Women who had had a pain event lasting three or more days previously were most likely to experience pain lasting two or more days during the subsequent menstrual period. Similarly, a woman who had previously experienced severe pain was most likely to experience moderate or severe pain during her subsequent menstrual period.

\section{Risk factors for menstrual pain}

Table 5 present the results of the multiple logistic regression analysis for the probability of having pain during a menstrual bleed. As would be expected, age at menarche, previous cycle length, and length of the current bleeding episode were all associated with having menstrual cramps. Pain was more likely to occur after longer menstrual cycles. Having a menstrual period longer than a week also increased a woman's odds of experiencing pain by about $90 \%$. There also appeared to be an important association between duration of bleed and age at menarche: in
Table 3. Probability of having a pain event of zero, one, two, or more than two days during the current bleeding episode by duration of pain event in previous bleeding episode (by-woman transition probabilitites for 165 women aged 17 to 19 years old).

\begin{tabular}{|c|c|c|c|c|}
\hline \multirow{2}{*}{$\begin{array}{l}\text { Duration of pain } \\
\text { event during previous } \\
\text { bleeding episode }\end{array}$} & \multicolumn{4}{|c|}{$\begin{array}{l}\text { Duration of pain event during } \\
\text { current bleeding episode }\end{array}$} \\
\hline & No pain & 1 day & 2 days & $\geq 3$ \\
\hline No Pain & 0.46 & 0.24 & 0.20 & $0 \cdot 11$ \\
\hline 1 day & $0-28$ & 0.33 & 0.27 & $0 \cdot 13$ \\
\hline 2 days & $0 \cdot 22$ & $0 \cdot 25$ & $0 \cdot 25$ & 0.29 \\
\hline$\geq 3$ & 0.16 & $0 \cdot 13$ & 0.33 & 0.38 \\
\hline
\end{tabular}

Table 4. Probability of having no, mild, moderate, or severe pain during the current bleeding episode by severity of pain event in previous bleeding episode (by woman transition probabilitites for 165 women aged 17 to 19 years old).

\begin{tabular}{lcccc}
\hline & \multicolumn{4}{c}{$\begin{array}{c}\text { Severity of pain during } \\
\text { current bleeding episode }\end{array}$} \\
$\begin{array}{l}\text { Severity of pain } \\
\text { during previous } \\
\text { bleeding episode }\end{array}$ & No pain & Mild & Moderate & Severe \\
\cline { 2 - 5 } & & & & \\
No Pain & 0.46 & 0.22 & 0.16 & 0.17 \\
Mild & 0.27 & 0.32 & 0.23 & 0.18 \\
Moderate & 0.18 & 0.25 & 0.29 & 0.28 \\
Severe & 0.14 & 0.24 & 0.30 & 0.32 \\
\hline
\end{tabular}

women whose menarche began at age 11 , the odds of having pain were increased threefold if their menstrual period exceeded seven days, compared with an increased odds of $70 \%$ if bleeding lasted seven days or less. Other than these menstrual characteristics, only two individual risk factors were associated with the probability of having pain: very heavy women had about a $75 \%$ increase in their odds of having menstrual cramps, while women who were frequent consumers of alcohol had about a $30 \%$ decrease.

Table 6 presents the results of the analysis of risk factors for having moderate to severe pain or pain that lasted more than two days given the occurrence of menstrual cramps. In addition to their increased probability of having any pain, women with an earlier age at menarche had a slight increase in the odds of having more severe pain and a longer pain event. The odds of having a longer duration of pain were increased slightly in longer menstrual cycles, but long cycles were not associated with pain severity. Heavy women had more than twice the odds, and current smokers had a $50 \%$ increase in the odds, of having pain lasting more than two days. Although frequent alcohol consumption decreased the probability of having any pain, it appeared to increase the odds of having severe pain and pain lasting more than two days. Women living away from home were $50 \%$ less likely to experience severe pain. 
Table 5. Multiple logistic regression with robust variance estimation on probability of having menstrual pain for 140 women aged 17 to 19 years old. Values are given as odds ratios (OR) and $95 \%$ confidence intervals (CI).

\begin{tabular}{|c|c|c|}
\hline & OR & $(95 \% \mathrm{CI})$ \\
\hline \multicolumn{3}{|l|}{ Menstrual cycle length (days) } \\
\hline 21 & 0.73 & $(0.56-0.95)$ \\
\hline 25 & 0.85 & $(0.75-0.97)$ \\
\hline 29 & - & \\
\hline 35 & $1 \cdot 27$ & $(1 \cdot 04-1 \cdot 54)$ \\
\hline 42 & 1.67 & $(1 \cdot 09-2 \cdot 55)$ \\
\hline Bleed duration $>7$ days & 1.90 & $(1 \cdot 29-2 \cdot 80)$ \\
\hline \multicolumn{3}{|c|}{ Age at menarche (years) by bleed duration } \\
\hline \multicolumn{3}{|c|}{ Bleed $\leq 7$ days } \\
\hline 11 & $1 \cdot 77$ & $(1 \cdot 12-2 \cdot 79)$ \\
\hline 12 & 1.33 & $(1.06-1 \cdot 67)$ \\
\hline 13 & - & \\
\hline 14 & 0.75 & $(0.60-0.94)$ \\
\hline 15 & 0.56 & $(0.36-0.89)$ \\
\hline \multicolumn{3}{|l|}{ Bleed $>7$ days } \\
\hline 11 & $3 \cdot 23$ & $(1.92-5 \cdot 44)$ \\
\hline 12 & $1 \cdot 80$ & $(1 \cdot 38-2 \cdot 33)$ \\
\hline 13 & - & \\
\hline 14 & 0.56 & $(0 \cdot 43-0 \cdot 72)$ \\
\hline 15 & $0 \cdot 31$ & $(0 \cdot 18-0 \cdot 52)$ \\
\hline 90th Centile of weight-for-height & 1.74 & $(0 \cdot 72-4 \cdot 20)$ \\
\hline Alcohol consumed > once/week & $0 \cdot 76$ & $(0.53-1.09)$ \\
\hline
\end{tabular}

The major risk factor for taking pain medication was the severity and duration of a pain episode, with the odds of taking medication increased two and a half-fold (OR 2.53, 95\% CI 1.85-3.45) during episodes of moderate to severe pain and $50 \%$ during long pain events (OR 1.54, 95\% CI 1.10-2.11). Frequent alcohol consumption (OR 1.58) and a history of long cycles (OR 1.68) also increased the odds of self-medication, although the confidence intervals include one. Similarly, the major determinant of missing an activity during the menstrual period was severity of cramps (OR 6.48, 95\% CI 3.50-11.97), although women were less likely to miss an activity during periods of high stress (OR 0.54).

Onset of cramps before bleeding was strongly associated with having an early age at menarche (OR $1 \cdot 54,95 \%$ CI $1 \cdot 05-2 \cdot 26$ for menarche at age 12 versus age 13) and having a long menstrual cycle (OR 1.49 , 95\% CI 1.11-1.99 for 35 versus 29 days). After adjusting for age at menarche, bleed length, and menstrual cycle length, the probability of having pain begin before menstruation was associated with a history of having menstrual cycles longer than 43 days (OR 1.60), smoking (OR 1.51), and being at the 90 th centile of perceived stress (OR $1 \cdot 81,95 \% \mathrm{CI}$ 1.04-3.15).

Multiple pain episodes were most likely to occur during long bleeds (OR 3.21, 95\% CI 1.49-6.88) and were more common following long menstrual cycles
Table 6. Multiple logistic regression with robust variance estimation on the probability (given the occurrence of pain) that pain would be severe or last longer than two days in 130 women aged 17 to 19 years who experienced pain during at least one menstrual period. Values are given as odds ratios and $95 \%$ confidence intervals.

\begin{tabular}{|c|c|c|}
\hline & $\begin{array}{l}\text { Severe Pain } \\
\text { OR }(95 \% \mathrm{CI})\end{array}$ & $\begin{array}{l}\text { Last }>2 \text { days } \\
\text { OR }(95 \% \text { CI })\end{array}$ \\
\hline \multicolumn{3}{|l|}{ Age at menarche (years) } \\
\hline 11 & $1.43(0.95-2.15)$ & $1 \cdot 38(0 \cdot 90-2 \cdot 11)$ \\
\hline 12 & $1.20(0.97-1.47)$ & $1 \cdot 17(0.95-1.45)$ \\
\hline 13 & - & - \\
\hline 14 & $0.84(0.68-1.03)$ & $0.85(0.69-1.05)$ \\
\hline 15 & $0.71(0.46-1.06)$ & $0.72(0.47-1 \cdot 11)$ \\
\hline Bleeding episode $>7$ days & $1.38(0.83-2.31)$ & $1.41(0.89-2 \cdot 24)$ \\
\hline \multicolumn{3}{|l|}{ Menstrual cycle length (days) } \\
\hline 21 & & $0.79(0.60-1.05)$ \\
\hline 25 & & $0.89(0.78-1.02)$ \\
\hline 29 & & - \\
\hline 35 & & $1.19(0.97-1.46)$ \\
\hline 42 & & $1.45(0.93-2.28)$ \\
\hline Living away from home & $0.67(0.50-0.89)$ & \\
\hline Alcohol consumed $>$ once/week & $1 \cdot 38(0 \cdot 84-2 \cdot 26)$ & $1.95(1.25-3.04)$ \\
\hline Smoker & & $1.52(0.82-2.82)$ \\
\hline 90th centile of weight-for-height & & $2 \cdot 46(1 \cdot 16-5 \cdot 19)$ \\
\hline
\end{tabular}

(OR $1 \cdot 42,95 \%$ CI $1 \cdot 08-1 \cdot 86$ for 35 versus 29 days). After adjusting for age at menarche, bleed length, and menstrual cycle length, the odds of a having multiple pain episodes were more than doubled in smokers (OR $2 \cdot 44,95 \%$ CI $1 \cdot 14-5 \cdot 23$ ), nearly doubled in heavy women (OR 1.9) and increased by more than $50 \%$ in women with a history of menstrual cycles more than 43 days in duration (OR 1.55), or above the 90th centile of weight-for-height (OR 1.69). Unusual pain patterns, in which pain increased during the bleeding episode rather than decreasing, were most common in heavy women (OR 1.70) and in women who lived away from home (OR 1.47, 95\% CI 1·05-2.05).

\section{DISCUSSION}

This study estimated the probability of recurrent severe dysmenorrhoea and identified risk factors for the occurrence of menstrual cramps, as well as risk factors associated with the severity and duration of a pain event in a cohort of 17 to 19 year old college women. An important finding is the association between being overweight and the occurrence and duration of menstrual cramps. Additional findings that menstrual cycle characteristics, smoking, and frequent alcohol consumption influenced pain experience are consistent with previous findings from crosssectional studies. Physical activity, which has been associated with a decreased prevalence of pain among 
athletes $^{22}$, but not in the general population ${ }^{6,8,12}$, also was not associated with pain in this study.

Dysmenorrhoea is a common complaint and most women experience occasional episodes of severe pain. In this study $60 \%$ reported at least one episode of severe pain, a figure consistent with the $67 \%$ to $72 \%$ prevalences observed in cross-sectional studies of 17 to 24 year old women ${ }^{4,9-12}$. However, $13 \%$ of participants usually had severe pain, which is similar to the prevalence of severe pain reported in previous studies $^{1,11}$. It is this group with severe pain who are most likely to benefit from prophylactic therapy.

Data provided here on the probability of recurrent pain can assist clinicians in educating patients about menstrual cramps and provide useful guidelines for recommending prophylactic use of antiprostaglandin therapies. Women who experience a pain episode lasting three or more days have a $72 \%$ probability of having pain lasting at least two days during their next menstrual period, and these women may be advised to start pharmacologic therapy when menstruation begins and to continue therapy throughout the first two to three days of their menstrual period. Although Pullon et al. $^{6}$ found that more than half of adult women report menstrual cramps starting before menstruation, only $11 \%$ of the young women in this study experienced the onset of pain before menstruation. Thus, starting medication with the onset of bleeding may be adequate for most adolescent women.

Women who experience pain for two days have an equal probability of having either little to no pain or a long pain episode during their subsequent menstrual period. Doctors may wish to consider differences in individual levels of pain tolerance and patient attitudes towards medication in making recommendations about prophylactic therapy to this group of women. In either case, women who experience pain episodes lasting two to three days are an important group to target for discussions of effective pain management. Similarly, women who experience a severe pain episode have a $62 \%$ probability of experiencing moderate to severe pain during their subsequent menstrual period and may also want to consider prophylactic therapy.

It is well known that dysmenorrhoea is more likely to occur during ovulatory cycles and that, during the menarcheal transition, the probability of ovulation increases with age ${ }^{4,23,24}$. Three studies of adult women ${ }^{1,5,8}$ have also found an increased risk associated with early age at menarche. In this study women with an earlier age at menarche were more likely to report pain, to have longer and more painful episodes and to report pain starting before bleeding. Longer duration of bleeding increased the probability of having pain, particularly in women with an earlier age at menarche $e^{1,8,14}$, and of having longer, more severe pain or multiple pain episodes. The probability of having menstrual cramps, multiple pain episodes and onset of pain prior to bleeding also increased with length of the menstrual cycle. Thus, women who had menarche at age eleven or younger, who have cycles longer than 35 days or who experience periods lasting a week or longer might be counselled that they are more likely to experience menstrual pain.

In addition to a woman's menstrual history, certain modifiable lifestyle characteristics appear to increase the risk of dysmenorrhoea, and doctors may want to discuss potential health benefits of lifestyle changes. Most importantly, cross-sectional studies of reproductive age women have found that the prevalence and severity ${ }^{3,6,8}$ of menstrual cramps are elevated in smokers. In one case-control study, smoking 10 or more cigarettes per day increased the odds of having moderate/severe dysmenorrhoea by about $90 \%{ }^{14}$. In the current study only $5 \%$ of women smoked 10 or more cigarettes per day: Smoking was not associated with the probability of having pain, but among those with pain, smokers were more likely to have severe cramps, pain lasting longer than two days, multiple episodes of pain, and onset of pain before bleeding. The consistency of the literature on smoking suggests that use of tobacco is a risk factor for the occurrence of menstrual cramps and for prolonged pain episodes $^{8,25}$.

Parazzini et al. ${ }^{14}$ reported that, compared with women who do not drink alcohol, women who drank one to seven glasses of alcohol per week were slightly more likely to have dysmenorrhoea (OR 1.3), while those who drank more than seven glasses of wine per week were slightly less likely to have dysmenorrhoea (OR 0.8). In our dataset consumption of alcohol more than once per week appeared to decrease the probability of having menstrual cramps, but among those experiencing pain, drinking doubled the odds of pain lasting more than two days. Frequent drinkers were also more likely to report self-medication. Since alcohol appears to have both a suppressive and a potentiating action on dysmenorrhoea, women should probably be counselled against self-medication with alcohol, and popular notions of the efficacy of alcohol should be questioned.

Being overweight was also an important risk factor for the probability of experiencing pain and for increasing duration of pain, even after adjusting for cycle length and duration of bleed. Although being overweight is known to affect menstrual cycle length and the probability of amenorrhea ${ }^{15,26,27}$, no previous studies have identified weight as a potential risk factor for dysmenorrhoea ${ }^{1,6,8}$. In this study the effect of being overweight was limited to the 
90th centile of weight for height. Obesity may have an oestrogen mediated-effect on endometrial thickness or a prostaglandin-mediated effect on bleed efficiency. Heavy women report greater flows ${ }^{28}$ but also have shorter menstrual bleeds ${ }^{29,30}$. In either case, obese women may be another appropriate group for prophylactic therapy.

The major limitation of this study was the lack of endocrinologic measures of ovarian activity to assess whether a given menstrual cycle was anovulatory. However, factors associated with anovulation, such as living away from home, did have the expected effect of reducing menstrual pain. Also, pain is a subjective phenomenon which can be difficult to measure accurately. In this study we tried to disaggregate various pain parameters, including the occurrence, amount, duration and pattern of pain, and to evaluate separately the impact of potential risk factors on each component. The possibility of biases resulting from censoring and from nonresponse of participants was considered, and neither initial willingness to participate in the diary study nor duration of follow up was associated with a woman's pain experience. Generalisation of the findings is limited by the restricted age range of the study population, but findings are consistent with those from older populations. Future studies should assess additional environmental risk factors, such as working conditions, noise, and diet $t^{31,32}$.

In summary, this is the first prospective diary study of dysmenorrhoea. Many of the findings from previous cross-sectional studies, including the importance of smoking as a risk factor, were replicated. Young women who experience menstrual pain lasting three or more days or who report severe pain are good candidates for prophylactic therapy. Doctors might recommend that these women begin appropriate pharmacologic treatment when menstruation begins and continue treatment for two days. The profile of young women at greatest risk of experiencing menstrual cramps are those women who reached menarche at age 11 or younger, with frequent cycles longer than 35 days or with bleeds lasting a week or longer, and who are overweight. Alcohol appears to increase the severity of menstrual cramps and should not be recommended as a treatment.

\section{Acknowledgements}

Supported by Grant R29-HD30373 from the National Institute of Child Health and Human Development. The authors would like to thank Dr J. Randolph and Dr C. Sampselle for their comments on the manuscript, as well as Ms J. Olszewski for her assistance in the preparation of the manuscript.

\section{References}

1 Andersch B, Milsom I. An epidemiologic study of young women with dysmenorrhea. Am J Obstet Gynecol 1982; 144: 655-660.

2 Bang RA, Bang AT, Baitule M, Choudhary Y, Sarmukaddan S, Tale $O$. High prevalence of gyneacological diseases in rural Indian women. Lancet $1989 ; 1$ : 85-88.

3 Brown S, Vessey M, Stratton I. The influence of method of contraception and cigarette smoking on menstrual patterns. Br J Obstet Gynaecol 1988; 95: 905-910.

4 Klein JR, Litt IF. Epidemiology of adolescent dysmenorrhea. Pediatrics 1981; 68: 661-664.

$5 \mathrm{Ng} \mathrm{TP}$, Tan NCK, Wansaicheong GKL. A prevalence study of dysmenorrhoea in female residents aged 15-54 years in Clementi Town, Singapore. Ann Acad Med Singapore 1992; 21: 323-327.

6 Pullon S, Reinken J, Sparrow M.. Prevalence of dysmenorrhoea in Wellington women. NZMed J 1988; 101: 52-54.

7 Sloss EM, Frerichs RR. Smoking and menstrual disorders. Int $J$ Epidemiol 1983; 12: 107-109.

8 Sundell G, Milsom I, Andersch B. Factors influencing the prevalence and severity of dysmenorrhoea in young women. $\mathrm{Br} J$ Obstet Gynaecol 1990; 97: 588-594.

9 Svanberg L, Ulmsten U. The incidence of primary dysmenorrhea in teenagers. Arch Gynecol 1981; 230: 173-177.

10 Thomas KD, Okonofua FE, Chiboka O. A study of the menstrual patterns of adolescents in Ile-Ife, Nigeria. Int J Gynecol Obstet 1990; 33 $1-4$.

11 Widholm O. Dysmenorrhea during adolescence. Acta Obstet Gynecol Scand Suppl 1979; 87: 61-66.

12 Wilson C, Emans SJ, Mansfield J, Podolsky C, Grace E. The relationships of calculated percent body fat, sports participation, age, and place of residence on menstrual patterns in healthy adolescent girls at an independent New England high school. $J$ Adolesc Health Care 1984; 5: 248-253.

13 Wood C. Gynaecological survey in a metropolitan area of Melbourne. Aust NZJ Obstet Gynaecol 1972; 12: 147-156.

14 Parazzini F, Tozzi L, Mezzopane R, Luchini L, Machini M, Fedele L. Cigarette smoking, alcohol consumption, and risk of primary dysmenorrhea. Epidemiology 1994; 5: 469-472.

15 Harlow SD, Matanoski GM. The association between weight, physical activity and stress and variation in the length of the menstrual cycle. Am J Epidemiol 1991; 133: 38-49.

16 Harlow SD, Zeger SL. An application of longitudinal methods to the analysis of menstrual diary data. $J$ Clin Epidemiol 1991; 44 $1015-1025$.

17 Rodriguez G, Faundes-Latham A, Atkinson LE. An approach to the analysis of menstrual patterns in the critical evaluation of contraceptives. Studies in Family Planning 1976; 7: 42-51.

18 Benn RT. Some mathematical properties of weight-for-height indices used as measures of adiposity. Br J Prev Soc Med 1971; 25: 42-50.

19 Florey CV. The use and interpretation of ponderal index and other weight-height ratios in epidemiologic studies. J Chron Dis 1970; 23: 93-103.

20 Cohen S, Kamarck R, Mermelstein R. A global measure of perceived stress. J Health Soc Behav 1983; 24: 385-396.

21 Zeger S L, Liang KY. Longitudinal data analysis for discrete and continuous outcomes. Biometrics 1986; 42: 121-130.

22 Okonofua FE, Balogun JA, Ayangade SO, Fawole JO. Exercise and menstrual function in Nigerian university women. Afr J Med Sci 1990; 19: $185-190$.

23 Doring GK. The incidence of anovular cycles in women. $J$ Reprod Fert 1969; 6 Suppl: 77-81.

24 Metcalf MG. Incidence of ovulation from the menarche to the menopause: observations of 622 New Zealand women. $N Z$ Med $J$ 1983; 96: 645-648.

25 Akerlund M, Bengtsson LP, Carter AM. A technique for monitoring endometrial or decidual blood flow with an intrauterine thermistor probe. Acta Obstet Gynecol Scand 1995; 54: 469-477.

26 Friedman CI, Kim MH. Obesity and its effect on reproductive function. Clin Obstet Gynecol 1985; 28: 645-663.

27 Harlass FE, Plymate SR, Fariss BL, Belts RP. Weight loss is associated with correction of gonadotropin and sex steroid abnormalities in the obese anovulatory female. Fertil Steril $1984 ; 42$ : 649-652. 
28 Hartz AJ, Barboriak PN, Wong A, Katayama KP, Rimm AA. The association of obesity with infertility and related menstrual abnormalities in women. Int JObesity 1979; 3: 57-73.

29 Belsey E M, d'Arcangues C, Carlson N. Task force on long-acting systemic agents for fertility regulation. Determinants of menstrual bleeding patterns among women using natural and hormonal methods of contraception II. The influence of individual characteristics. Contraception 1989; 38: 243-257.

30 Harlow SD, Campbell BC. Host factors that influence the duration of menstrual bleeding. Epidemiology 1994; 5: 352-355.
31 Harlow SD, Ephross SA. Epidemiology of menstruation and its relevance to women's health. Epidemiol Rev 1995; 17: 265-286.

32 Mergler D, Vezina N. Dysmenorrhea and cold exposure. $J$ Reprod Med 1985; 30: 106-111.

Received 27 September 1995

Accepted 2 May 1996 